\title{
Experimental Study on the Influence of AC Stray Current on the Cathodic Protection of Buried Pipe
}

\author{
Qingmiao Ding and Yueming Fan \\ Airport School, Civil Aviation University of China, Tianjin 300300, China \\ Correspondence should be addressed to Qingmiao Ding; qmding@cauc.edu.cn
}

Received 25 September 2015; Revised 4 December 2015; Accepted 29 December 2015

Academic Editor: Flavio Deflorian

Copyright (C) 2016 Q. Ding and Y. Fan. This is an open access article distributed under the Creative Commons Attribution License, which permits unrestricted use, distribution, and reproduction in any medium, provided the original work is properly cited.

\begin{abstract}
The size of the damaged area of the coating and its position on the pipeline impacted the cathodic protection potential, and there was a damaged area of the greatest impact value. When damaged area was $300 \mathrm{~mm}^{2}$, the IR drop was the largest, and this situation could easily lead to inadequate protection; when the parallel spacing between pipeline and interference source was unchanged, the measured value curves of cathodic protection potential presented " $U$ " shaped trend with the increasing stray current interference intensity. Under certain parallel spacing between pipeline and interference source, high alternating stray current intensity would cause serious negative offsets, so that the overprotection of the pipeline occurred, and make the coating crack; there was a parallel threshold length. When less than the threshold, the pipe-ground potential increases rapidly with the parallel length increasing. In order to judge whether a pipeline was interference by AC stray current and the risk of stray current corrosion, we should make a comprehensive analysis of the cathodic protection energizing potential, the switch-off potential, AC pipe-soil potential, IR drops, and so on.
\end{abstract}

\section{Introduction}

With the continuous development of energy, electric power, and railway transportation, oil or gas pipelines may run parallel with overhead AC high voltage power lines and ACpowered electric railway or sometimes even cross them in developed areas or geographically special corridor regions $[1,2]$. Because of the inherent power supply mode and characteristics of the electrified railway traction power supply system, it is impossible to be completely ground insulated [3], and, due to electromagnetic induction coupling effect of overhead lines, buried pipelines are inevitably under the interference of stray current corrosion [4-7]. In the process of field survey of cathodic protection condition, though the measured cathodic protection potential had reached the conventional protection criterion, $-850 \mathrm{mV}$ (CSE), it was found that AC corrosion damage still occurred in some places and insulating coating [8-10], and cathodic protection system of oil and gas pipelines were likely to be affected by stray currents [11], which is not of benefit to the reliable operation of the pipeline and integrity management. Therefore, based on electrified railway system structure and the characteristics of the electrical circuit, this paper designed indoor stray current interference experiment. It studied the interference principle of the cathodic protection system caused by stray current, which had a practical significance to direct stray current survey and current drain of oil and gas pipelines.

\section{Experiment}

By controlling variables to reduce interference effect on experiment result and improve its reliability, we build an uncovered box, whose external material is wooden and the internal material is PVC. Loess was used for its good moisture retention. During and after the experiment, soil surface was covered with nylon type to prevent soil electrical resistance changing. Before each experiment, trace tested solid electrical resistance. It would not begin until soil resistance values were the same.

AS shown in Figure 1, simulated buried pipeline with the material of Q235 pipeline steel $(\mathrm{DN} 20 * 2.5)$ is $3.00 \mathrm{~m}$ in length and $0.50 \mathrm{~m}$ in depth. The external wall of steel pipe was painted by insulating paint and then tightly wrapped with waterproof insulation tape. For parameter measurement, 


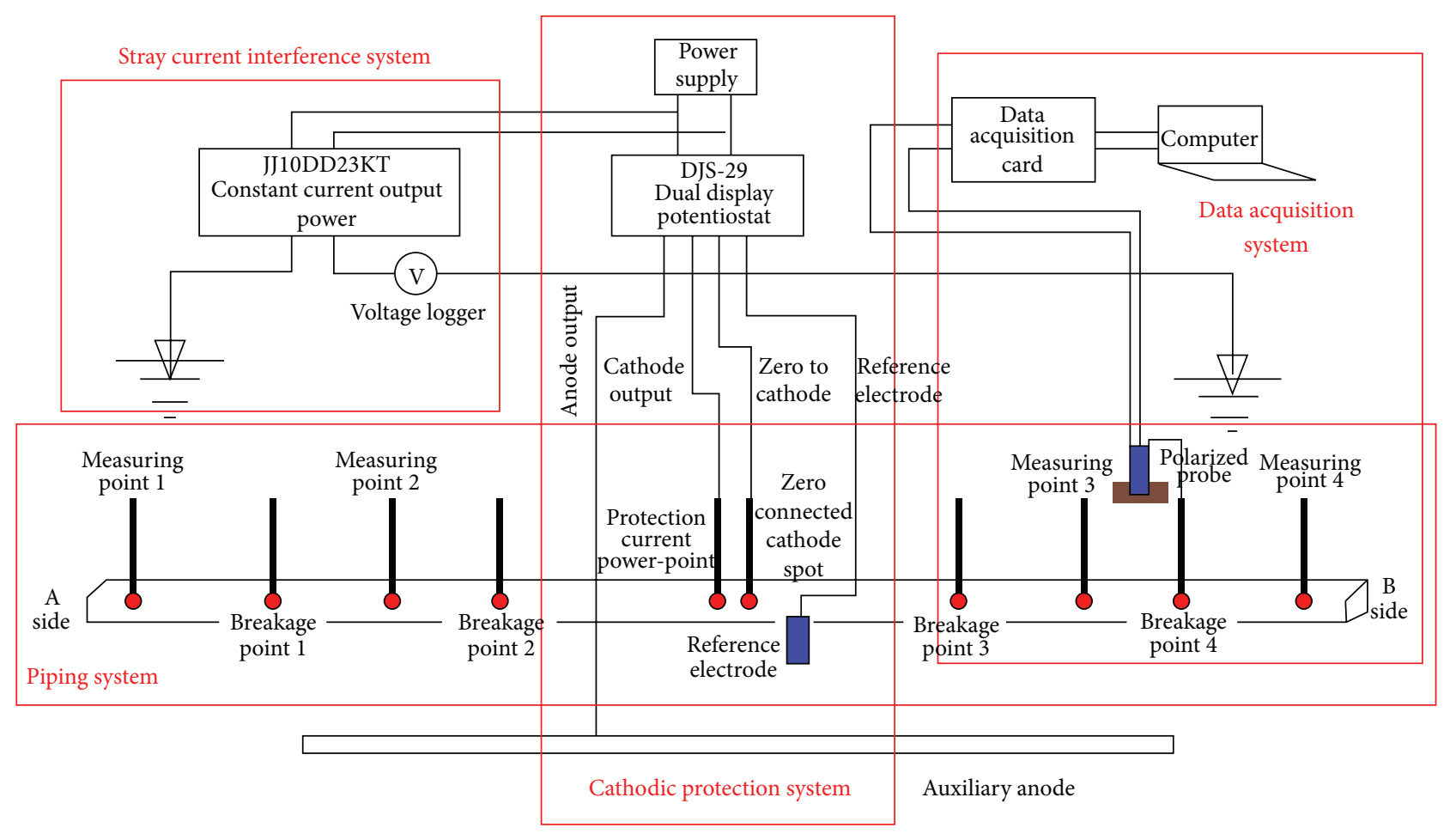

FIgURE 1: The schematic diagram of experimental facility.

wires were, respectively, welded on the pipes' lengths of $0 \mathrm{~m}, 0.80 \mathrm{~m}, 2.20 \mathrm{~m}$, and $3.00 \mathrm{~m}$. Test points had test blocks with different damage areas and orientations. Test blocks, whose material was the same with the pipes, were completely packaged in the epoxy resin paint and left the damaged area on the surface. In order to connect the circuit, copper wires were welded on the opposite side of the insulating coating with damaged area. Damaged areas of the exposed surface need to be polished, have oil removed with acetone, be wiped with anhydrous ethanol and dried, and then be set aside.

Buried pipeline was protected by the double-show potentiometer, DJS-292, which provides constant potential cathodic protection. Wasted steel was used as auxiliary anode of the cathode protection system.

The current source whose number is JJ10DD23KT was used as stray current interference AC power. Copper strikes were used as discharge electrodes and reflow electrode, which has low resistance and good contact. To better simulate the stray current leak in the way of point power on spot, electrodes were bound with waterproof insulation tape, leaving its ends to $20 \sim 30 \mathrm{~mm}$ to remain in contact with soil.

\section{The Results and Discussion}

3.1. The Influence of Coating Damage Area. Under the circumstance of different damage areas at the same point on the pipeline coating, we researched the interference influence that stray current had on the cathodic protection system. At damage point 1 , cut of the specimen was, respectively, set as $50,100,200,300,200$, and $625 \mathrm{~mm}^{2}$. The potentiometer output protection potential was controlled constantly to be
$-1.000 \mathrm{~V}$, interference intensity of AC stray current was $0.1 \mathrm{~A}$, and tube-rail parallel spacing was $0.6 \mathrm{~m}$.

By analyzing the cathodic protection potential, when the pipeline reached $0.1 \mathrm{~A} A C$ stray current interference, the real protection voltage [12] was, respectively, $U_{T \text {-pro }}=0.94767 \mathrm{~V}$ $>U_{I T \text {-pro }}=0.85712 \mathrm{~V}$, in which the real voltage decreased by $0.09055 \mathrm{~V}$. In spite of cathodic protection provided by the potentiometer, when the pipeline was under AC stray current interference, it was clear that the real protection voltage had declined.

The potential value statistics of different damage areas of the coating were shown in Table 1.

It could be seen that different pipeline anticorrosive coating damage areas have little impact on cathodic protection potential of the pipeline; with the increase of damaged area, cathodic protection potential decreased slightly but overall did not change that much. The stable measured value was about $-0.99 \mathrm{~V}$ and the stable real value was around $-0.95 \mathrm{~V}$. IR drop was basically less than $0.05 \mathrm{~V}$. Therefore, within the scope of certain length, different damaged area of the anticorrosive coating would have a little impact on the pipeline cathodic protection potential. However, it could be predicted that the decrease trend of cathodic protection potential would be significant with the increase of the pipe length and damaged area. Finally, it may reduce pipeline cathodic protection potential to the point of losing protection.

There existed stray current interference; with the increase of the damaged area on the pipeline coating, pipeline cathodic protection potential measurements had a tendency of decrease, and the change of protection potential real value was more complex. The measured protection potential value 
TABLE 1: The pipe-soil potential under different coating defect areas.

\begin{tabular}{|c|c|c|c|c|c|}
\hline $\begin{array}{l}\text { The defect area } \\
S_{\text {def }}\left(\mathrm{mm}^{2}\right)\end{array}$ & $\begin{array}{l}\text { The maximum value } \\
\text { of the moment } \\
\text { interference } U_{\max }(\mathrm{V})\end{array}$ & $\begin{array}{c}\text { The measuring } \\
\text { protection potential } \\
\text { without interference } \\
U_{M \text {-pro }}(\mathrm{V})\end{array}$ & $\begin{array}{l}\text { The real protection } \\
\text { potential without } \\
\text { interference } U_{T \text {-pro }}(\mathrm{V})\end{array}$ & $\begin{array}{c}\text { The measuring } \\
\text { protection potential } \\
\text { with interference } \\
U_{I M-\text { pro }}(\mathrm{V})\end{array}$ & $\begin{array}{l}\text { The real protection } \\
\text { potential with } \\
\text { interference } U_{I T-\text { pro }} \\
(\mathrm{V})\end{array}$ \\
\hline 50 & -1.523 & -1.000 & -0.948 & -1.034 & -0.857 \\
\hline 100 & -1.282 & -1.000 & -0.955 & -1.031 & -0.842 \\
\hline 200 & -1.354 & -0.998 & -0.951 & -1.030 & -0.847 \\
\hline 300 & -1.302 & -0.997 & -0.956 & -1.034 & -0.795 \\
\hline 400 & -1.455 & -0.992 & -0.946 & -1.020 & -0.812 \\
\hline 625 & -1.298 & -0.988 & -0.952 & -1.020 & -0.834 \\
\hline
\end{tabular}

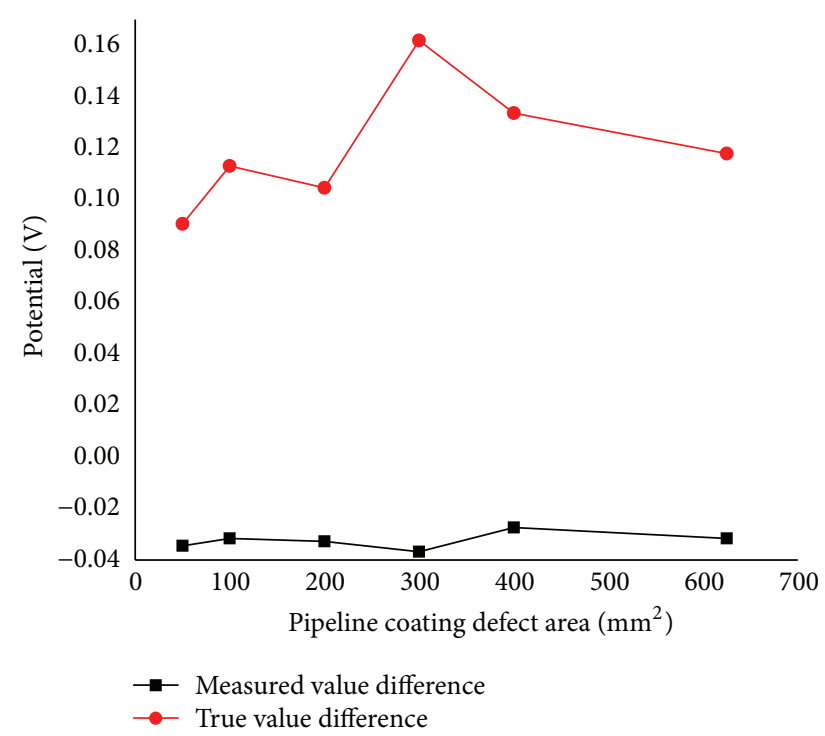

FIGURE 2: The potential difference curves of the measured value and true value along with defect areas.

with AC interference was greater than that without interference. However, the real protection potential value with inference was far less than the value without interference.

We drew the protective potential of measured value and true value difference along with the change of coating damage area under the same coordinate, as is shown in Figure 2.

By Figure 2, it could be found that protection voltage measurements rose before and after the inference, while real value declined. Along with the rising of the damaged area, the real value difference of the protected voltage first increased and then slowly decreased. When the damaged area reached $300 \mathrm{~mm}^{2}$, difference of the real value reached the maximum, namely, under the stray current interference; the real protection voltage was minimal while the damaged area was $300 \mathrm{~mm}^{2}$. Therefore, with pipeline affected by stray current interference, when pipeline anticorrosion coating area which is smaller than $300 \mathrm{~mm}^{2}$ was broken, the real value of pipeline cathodic protection gradually decreased and anticorrosion layer cut area increased; when anticorrosion coating area was more than $300 \mathrm{~mm}^{2}$, in the range of the experiments of the damaged area, protection voltage real value gradually rose, but the rate of increase was slow.

It could also be observed that the moment stray current interference happened, there would be a strong potential signal, and the size of the potential maximum $U_{\max }$ was beyond the value of the potentiometer, which could exceed more than $50 \%$ of the maximum value of the set value. At the same time, it could be seen that the potential extreme value showed the tendency of decrease with increase of damage area, suggesting that the smaller the pipeline anticorrosive coating damage area was or the better the coating quality was, the larger the strong voltage signal value influenced by AC interference was, which could lead to the greater effect on the cathodic protection system and coating. In the actual operation, therefore, we should pay attention to cathodic disbanding, in the small broken point interferenced by AC stray current.

3.2. The Impact of Parallel Spacing. We set the parallel length to $3.0 \mathrm{~m}$ without change, parallel spacing from $0.2 \mathrm{~m}$ to $1.0 \mathrm{~m}$, AC stray current interference intensity to $0.1 \mathrm{~A}$, and output voltage of cathodic protection system potentiometer to $-1.0 \mathrm{~V}$. We researched on influence on the cathodic protection system caused by AC stray current interference in the conditions of different length and spacing between pipeline and the parallel tracks.

During experiment, it was observed that potential at different rail spacing was changed periodically during the interference existing, and the period was about $40 \mathrm{~s}$. The time AC inference came out, pipe-to-soil potential abruptly changed, which remained about $3 \mathrm{~s}$. The potential value statics before and after interference were shown in Figure 3.

From Figure 3 the change rule of four curves about cathodic protection real values and measured values could be seen before and after pipeline was influenced by stray currents inference. Because the experiment parameters did not change without inference, the measured value of cathodic protection potential at different tube-rail spacing was about $0.95 \mathrm{~V}$. By the coupon OFF method, the real value was measured around $-0.90 \mathrm{~V}$, and IR drop was basically $0.05 \mathrm{~V}$. When pipe was affected by stray current interference, measured potential values in the state of cathodic protection decreased from $1.06 \mathrm{~V}$ to $0.98 \mathrm{~V}$ and pipe track spacing increased. While the trend of real value was contrary, which increased from about 


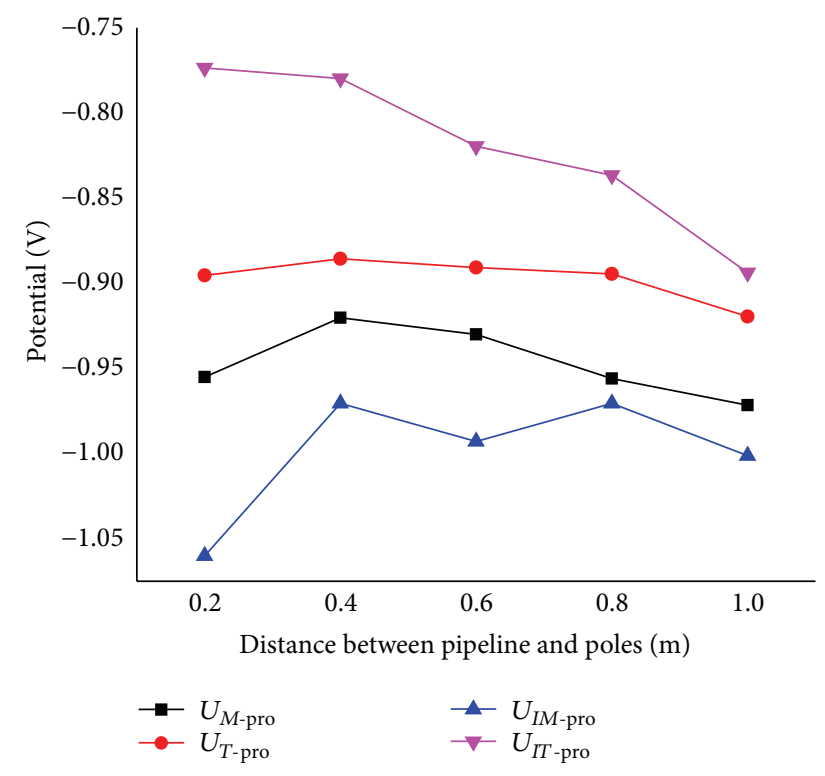

FIGURE 3: The potential curves under different parallel distance.

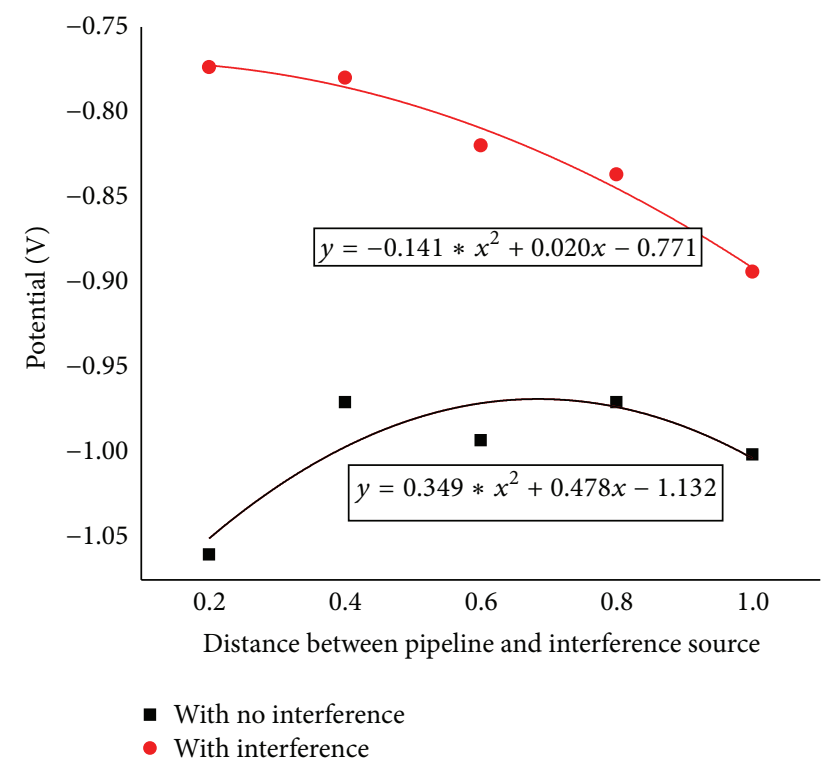

FIgURE 4: The measured and true potential curves under different parallel distance.

$-0.77 \mathrm{~V}$ to $-0.89 \mathrm{~V}$ or so, it was still less than the value without interference.

In order to further analyze the change relationship of the measured and real value in the condition of the stray current interference, we, respectively, drew the two curves, which is shown in Figure 4.

In Figure 4, formulas are both quadratic polynomial with high relative fitting degree.

IR drop equals the real values from measured values with inference subtraction. Drawing of the curve which reflected the relationship of IR drop and tube-rail distance is shown in Figure 5.

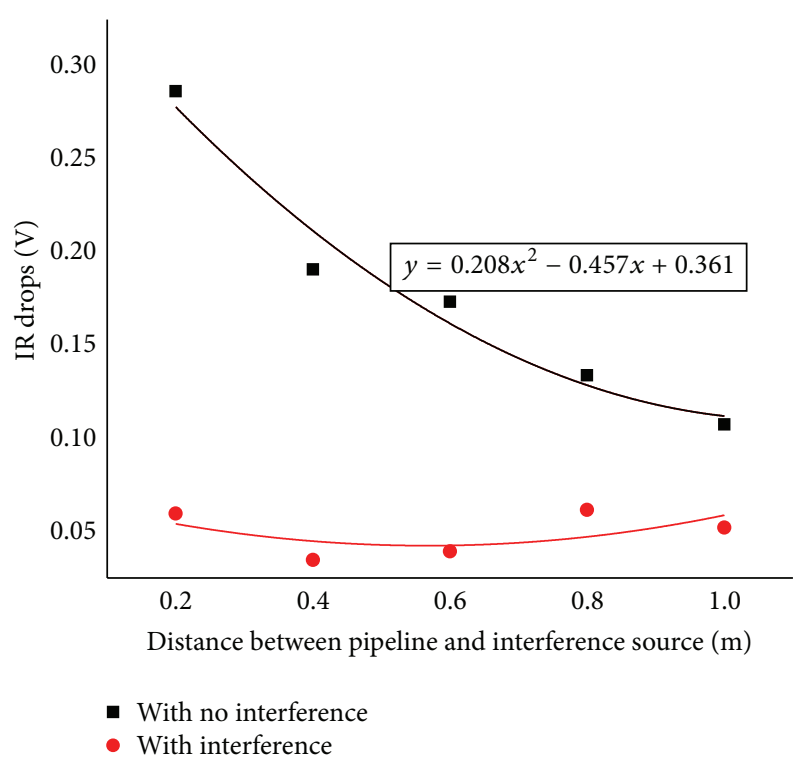

FIGURE 5: The IR drops curves along with parallel distance.

It could be observed that IR drop with no interference was small, basically $0.05 \mathrm{~V}$. When confronted with inference, the IR drop curve was the quadratic polynomial, and fitting degree was quite high. With the increase of tube track spacing, the IR drop constantly decreased and the rate of decreasing progressively grew smaller. That is, the greater the spacing, the smaller the IR drop caused by AC stray current, and the real potential value was more close to the measured value. At the same time, the IR drop caused by the stray current interference was greater than the IR drop without inference; thus pipeline protection would be declined from stray current. The further the pipeline and stray current interference sources were, the smaller the inference degree of pipeline was affected, and so was the IR drop.

\subsection{Effect of Parallel Length of Tube Track on the Cathodic} Protection System. Set AC stray current interference intensity to $0.1 \mathrm{~A}$, output protection voltage of the cathodic protection potentiometer to $-1.0 \mathrm{~V}$, tube spacing $D=0.3 \mathrm{~m}$, and parallel length $L$ from $0.5 \mathrm{~m}$ to $3.0 \mathrm{~m}$.

In the experimental process, the protection potential under the stray current interference was changed periodically, and the change period was about $40 \mathrm{~s}$. At the instant of stray current interference, the protective potential of different parallel length has a mutation value, and the duration was about $3 \mathrm{~s}$, but the potential curve of the parallel length, $0.5 \mathrm{~m}$, did not have a clear mutation. When the stray current interference disappeared, the tube ground potential was restored to the natural corrosion potential. The protective potential values of the stray current interference were shown in Table 2.

From Table $2 U_{\max }$ data could be seen, and tube-rail parallel length increased; high voltage signal at interference instant showed an increasing trend. When parallel length was $0.5 \mathrm{~m}$, there was no apparent high voltage signal. When parallel length was $3.0 \mathrm{~m}$, mutation signal voltage was up to 
TABLE 2: The relation between the parallel length and the potential.

\begin{tabular}{lccccc}
\hline $\begin{array}{l}\text { The } \\
\text { parallel } \\
\text { length }(\mathrm{m})\end{array}$ & $\begin{array}{c}U_{M \text {-pro }} \\
(\mathrm{V})\end{array}$ & $\begin{array}{c}U_{T \text {-pro }} \\
(\mathrm{V})\end{array}$ & $\begin{array}{c}U_{I M \text {-pro }} \\
(\mathrm{V})\end{array}$ & $\begin{array}{c}U_{I T \text {-pro }} \\
(\mathrm{V})\end{array}$ & $\begin{array}{c}U_{\max } \\
(\mathrm{V})\end{array}$ \\
\hline 0.5 & -0.968 & -0.934 & -0.983 & -0.893 & -0.998 \\
1.0 & -0.966 & -0.933 & -0.996 & -0.869 & -1.300 \\
1.5 & -0.967 & -0.934 & -1.017 & -0.859 & -1.315 \\
2.0 & -0.947 & -0.917 & -1.005 & -0.810 & -1.893 \\
2.5 & -0.952 & -0.922 & -1.003 & -0.810 & -1.365 \\
3.0 & -0.961 & -0.931 & -1.027 & -0.810 & -2.052 \\
\hline
\end{tabular}

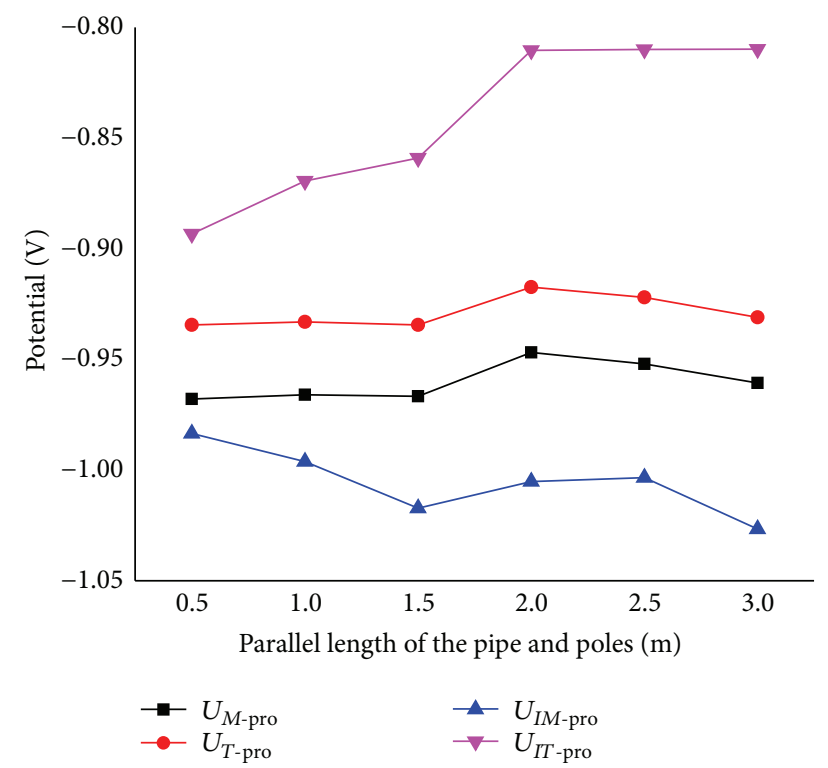

FIGURE 6: The potential curves along with the different parallel length.

$-2.052 \mathrm{~V}$, beyond $100 \%$ of the potentiostat setting value. It was shown that the longer the tube-rail parallel length was, the larger the interference voltage was and the bigger the interference on the cathodic protection system was.

Draw the protective potential with the variation of the parallel length as shown in Figure 6.

In Figure 6, with the situation without interference, the measured values of the potential curve and the real values curve are almost parallel, and the fluctuation was small, the IR was constant, and the base was $0.05 \mathrm{~V}$. However, to the situation with interference, with the increase of the parallel length of the tube, the value of the measured potential increased, but the value of the real potential decreased. The overall trend seemed to be that the longer the parallel length was, the greater the impact on the protection of the cathode was. On the surface, cathodic protection had reached protection requirements, even beyond the constant potentiometer settings; however, the real protection potential values were much smaller than the measured values and even far less than pipeline real protection potential which were

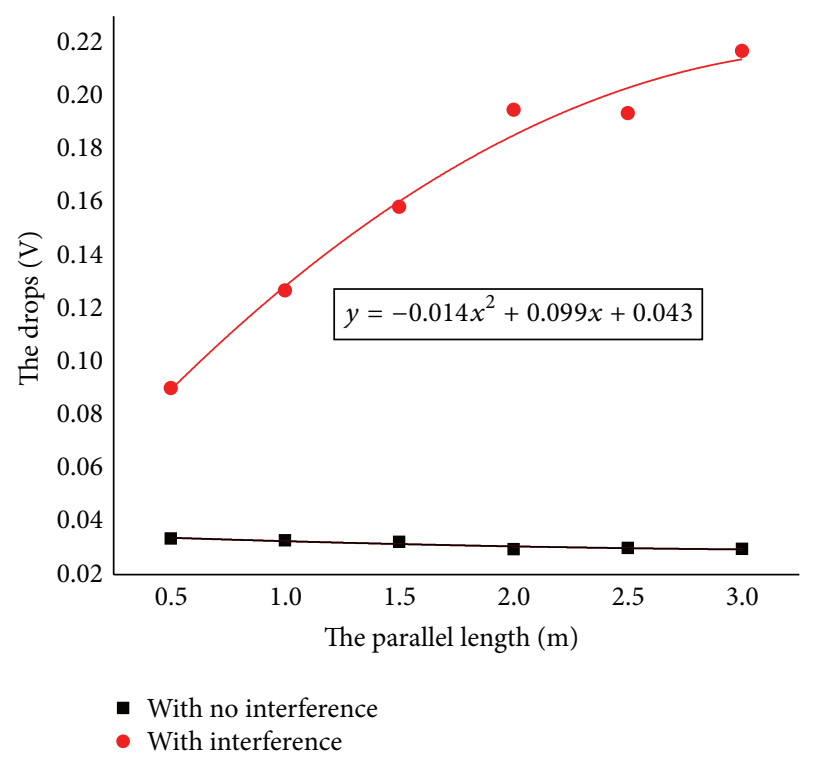

FIGURE 7: The IR drops curves before and after the AC interference.

not affected by the stray current interference at the same parallel length condition; the largest margin was up to $0.217 \mathrm{~V}$. From the curve of the true value of the protective voltage, the real value was maintained at about $-0.81 \mathrm{~V}$ after the parallel length exceeded $2.0 \mathrm{~m}$; meanwhile, the parallel length was decreased.

As could be seen from Figure 7, no stray current interference of the IR drop curve was almost linear, less than $0.04 \mathrm{~V}$; because of the experimental process, constant potential protection of all parameters did not have a change. Therefore, the protection of the current in the electrolyte of the IR drop was the same. However, with stray current interference, the protection potential of IR drop in the experimental tube section showed the logarithmic law. At the beginning of the IR drop in parallel increased with the length increasing rapidly and then increased slowly. And the IR value of the stray current, which was up to $0.2 \mathrm{~V}$, was far greater than that of the IR without interference. Therefore, the stray current could cause large IR drop component and reduce the degree of protection of the pipeline.

3.4. The Influence of AC Stray Current. In the experiment, the tube-rail parallel spacing was $0.2 \mathrm{~m}$, parallel length was $3.0 \mathrm{~m}$, and other external conditions were fixed, measuring pipeline cathodic protection potential when the stray current intensity varied from $0.1 \mathrm{~A}$ to $0.5 \mathrm{~A}$, getting the real protection potential by means of coupons.

During the experimental process, it was found that protection potential over time into periodic volatility changes by stray current interference, and the amplitude of the fluctuation increased with the increase of the intensity of the interference current, even lower than the natural corrosion potential of pipeline, variation period was $40 \mathrm{~s}$, and under different AC interference intensity curve shapes were also different. Taking the average potential value of a period as the measured potential interferenced by AC stray current, it can 


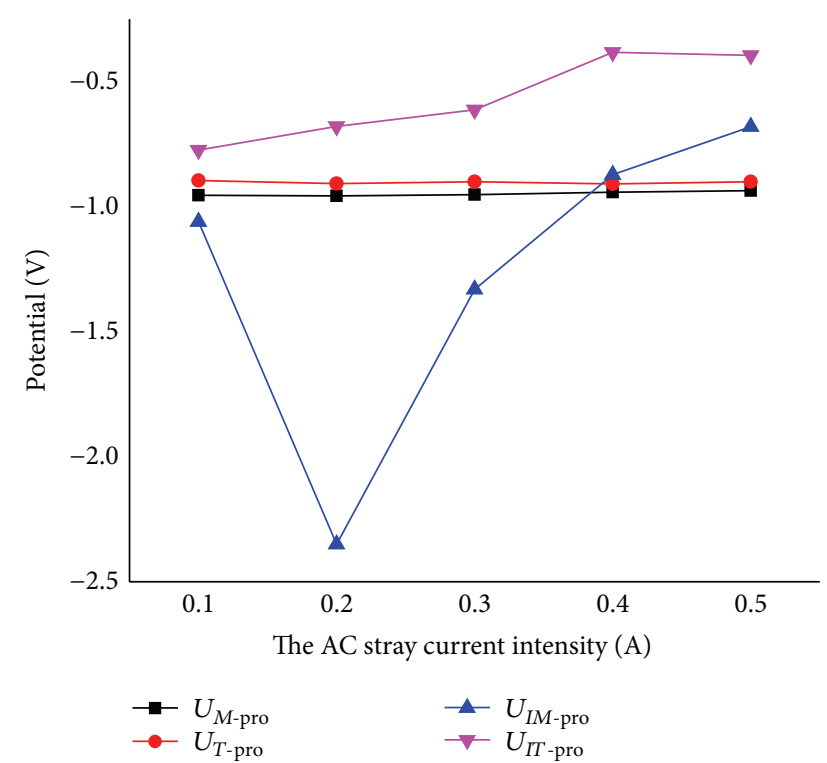

FIGURE 8: The potential value curves along with the AC stray current interference.

be seen that the potential would gradually fall back close to the natural corrosion potential when suddenly disconnecting the cathodic protection, but the potential drop would be under the natural corrosion potential and even be positive potential with the increasing interference current intensity. When the interference current was cut off, the potential of the tube was gradually restored to the neighbourhood of natural corrosion potential. The potential values of different disturbance intensities were shown in Figure 8.

The electric potential measurement values and the true values of the stray current interference were parallel to each other and were maintained close to $-0.90 \mathrm{~V}$ and $-0.95 \mathrm{~V}$, respectively. This was because various conditions of the cathodic protection did not change, and many times of measuring results do not change too much. The presence of stray current interference, as could be seen in the measuring potential value, first increased and then decreased with the increase of intensity of disturbance; measurement values under $0.4 \mathrm{~A}$ and $0.5 \mathrm{~A} \mathrm{AC}$ interference intensity were even lower than the potential measurements before interference. The real potential value with the increase of the interference decreased; in $0.4 \mathrm{~A}$ and $0.5 \mathrm{~A} \mathrm{AC}$ interference intensity of real value was even lower than the natural corrosion potential of pipeline, illustrating that pipeline corrosion rate will strengthen and within a short period of time can cause severe corrosion effect.

The experiment concentrated on the impact caused by stray current interference intensity in the spacing between the tube rails of $0.2 \mathrm{~m}$; for comparative analysis, experiments were conducted to the impact caused by stray current interference intensity in the condition of spacing between the tube rails of $0.4,0.6$, and $0.8 \mathrm{~m}$; contrasted results were shown in Figure 9.

From the curve in Figure 9, it could be found that the regularity of potential changed with the intensity of interference being very strong; the curve of potential measurement

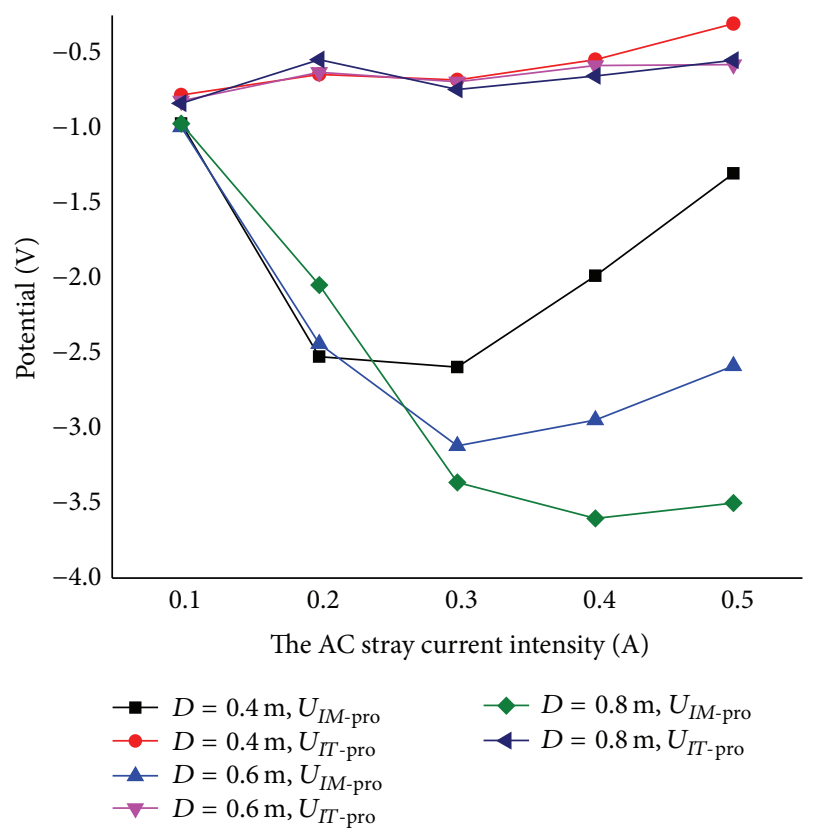

FIGURE 9: The potential curves along with AC interference intensity under different parallel distance.

values with the interference increasing first increased and then decreased, showing a " $U$ " shaped curve concave; parallel distance was greater and " $U$ " shaped curve was deeper. Curves in the $0.1 \mathrm{~A}$ and $0.2 \mathrm{~A}$ stray current interference were coincidence basically; the curve of measurement value by the interference intensity exceeded $0.2 \mathrm{~A}$ showing a divergence; the greater the parallel length was, the greater the potential value of the measurement was. The varying curves of the real potential values of the stray current interference in different tube-rail spacing are basically coincident. These real potential values decreased with the increase of the interference, but the rate of the decrease was slow.

3.5. Cathode Protection Output Voltages. Set the output voltage of potentiometer from $-0.85 \mathrm{~V}$ to $-1.50 \mathrm{~V}$; the stray current interference intensity was $0.1 \mathrm{~A}$ and the parallel distance and length were $3.0 \mathrm{~m}$ and $0.6 \mathrm{~m}$, respectively. Plot curve of potential with the output voltage is shown in Figure 10.

From Figure 10, we could see that the measured value of the protective potential before and after the interference and the real value before the interference, with the output voltage value of the constant potentiometer increasing, both presented a linear change. The true value after interference with output voltage of constant potentiometer increasing showed $\mathrm{S}$-shaped increasing trend, in the output voltage of $-1.15 \mathrm{~V}$ to $-1.35 \mathrm{~V}$ range; before and after the interference potential real value difference was very big; the real potential value was gradually approaching before and after the interference when the output voltage was less than $-1.15 \mathrm{~V}$ or greater than $-1.35 \mathrm{~V}$.

At the same time, through analysing IR drop before and after the interference, it could be found that the IR drop before the interference increases linearly with the increase in the 
TABLE 3: The potential value under different defects connection.

\begin{tabular}{lcccc}
\hline & $\begin{array}{c}U_{M-\text { pro }} \\
(\mathrm{V})\end{array}$ & $\begin{array}{c}U_{T-\text { pro }} \\
(\mathrm{V})\end{array}$ & $\begin{array}{c}U_{I M-\text { pro }} \\
(\mathrm{V})\end{array}$ & $\begin{array}{c}U_{I T \text {-pro }} \\
(\mathrm{V})\end{array}$ \\
\hline $\begin{array}{l}\text { Only 1 point damage } \\
\text { Point 1 and point 2 } \\
\text { damage }\end{array}$ & -1.000 & -0.955 & -1.031 & -0.842 \\
$\begin{array}{l}\text { Point 3 and point 2 } \\
\text { damage }\end{array}$ & -0.935 & -0.906 & -0.955 & -0.814 \\
$\begin{array}{l}\text { Point 4 and point 2 } \\
\text { damage }\end{array}$ & -0.935 & -0.904 & -0.944 & -0.828 \\
\hline
\end{tabular}

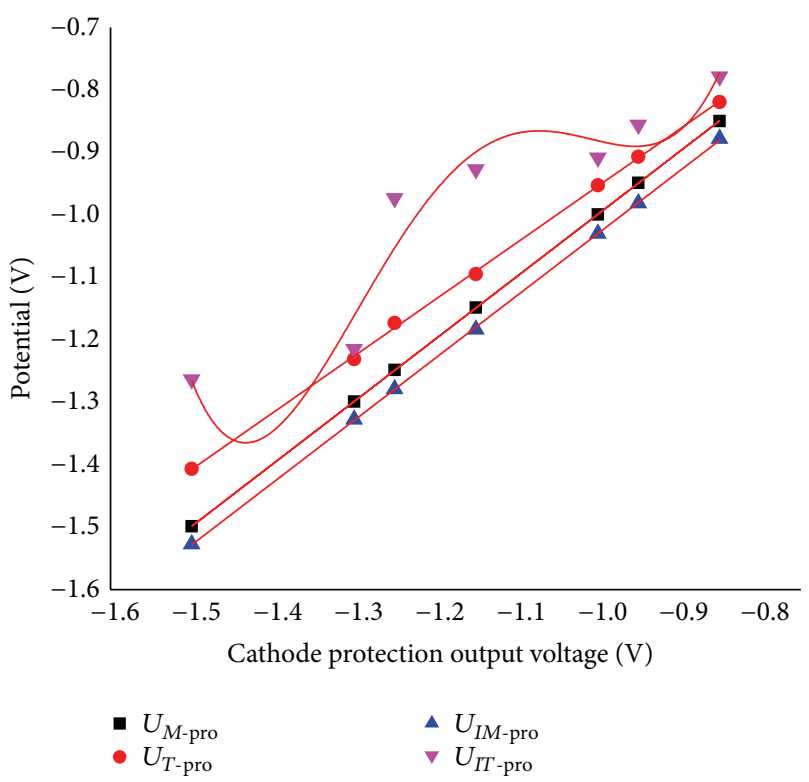

Figure 10: The potential curve along with different output CP voltage.

output value of the protection voltage, and the IR drop is the maximum between $-1.35 \mathrm{~V}$ and $-1.15 \mathrm{~V}$.

\subsection{Effects of Single Point Damage and 2-Point Damage on the} Anticorrosion Layer. Under the condition of the anticorrosion layer damaged area was $100 \mathrm{~mm}^{2}$, studying stray current interference effects at the condition of different locations along the tube length direction which appeared damaged. In the experimental study, the effects of 1-point single damage, 1-point and 2-point damage at the same time, 3-point and 2-point damage at the same time, and 4-point and 2-point damage at the same time on the cathodic protection were studied. The results were shown in Table 3 .

From Table 3, the data analysis showed both the measurement value and the true value of the potential when 1 point of damage is bigger than the values of two points of damage, respectively. Before the interference, the measured values of the negative and the real values of the negative were basically the same when three different groups of damaged points linked, and the value of IR drop was lower; it basically was about $0.03 \mathrm{~V}$. Under the interference, the measured values of the negative protection potential were basically the same when three different groups of damaged points linked, but the real value of the negative protection potential had difference; the maximum difference was $0.025 \mathrm{~V}$ and IR drop was about $0.14 \mathrm{~V}$. From the analysis above, it could be seen that when the damage points of the pipeline were less, the protective potential of the pipeline was high, but the protective potential was low when the damage points were many, and the potential difference was not great when the quantity of damage points was the same.

\section{Conclusion}

Through curves of potential, with time obtained from various experiments, the protection potential under the stray current interference was changed periodically, and the change period was about $40 \mathrm{~s}$. Meanwhile, when the intensity of interference was low, the protective potential had a mutation value at the instant of stray current interference, and the duration was about $3 \mathrm{~s}$.

With alternate stray current interference, when the damaged area was $300 \mathrm{~mm}^{2}$, real value of protected voltage was minimum. When the damage area of pipeline anticorrosion layer was less than $300 \mathrm{~mm}^{2}$, the effect by pipeline cathodic protection increased with damaged area of anticorrosion layer increasing; real value of protected voltage was small more and more; when the damage area of anticorrosion layer was more than $300 \mathrm{~mm}^{2}$, which was in the range of damaged area verified by experiment, true value protected voltage gradually increased, but the increasing rate was slow.

With the increase of the distance of parallel, IR drop caused by stray current interference decreased. Overall trend seemed to be that the longer the parallel length was, the bigger the influence on cathodic protection was; after parallel length increased to more than $2.0 \mathrm{~m}$, the true value basically maintained at a constant value, the effect on the cathodic protection was essentially the same with the parallel length increasing.

With the increase of the stray current interference, the measurement value curve of protective potential first increased and then decreased, and the " $U$ " shaped trend was presented. Real potential value curves are basically coincident and, under different tube track spacing, decreased gradually with increase of the intensity of interference, but the speed of decreasing was slow; real values under $0.4 \mathrm{~A}$ and $0.5 \mathrm{~A}$ $\mathrm{AC}$ interference intensity were even lower than the natural corrosion potential of pipeline, illustrating that pipeline corrosion rate will strengthen and within a short period of time can cause severe corrosion effect.

With the increase of the output voltage of the cathode protection, the measured value of the protective potential before and after the interference and the real value before the interference both presented a linear change. The true value after interference showed S-shaped increasing trend, in the output voltage of $-1.15 \mathrm{~V}$ to $-1.35 \mathrm{~V}$ range; before and after the interference potential real value difference was very big and he real potential value was gradually approaching before and after the interference when the output voltage was less than $-1.15 \mathrm{~V}$ or greater than $-1.35 \mathrm{~V}$. 


\section{Conflict of Interests}

The authors declare that there is no conflict of interests regarding the publication of this paper.

\section{Acknowledgments}

The research work was supported by the Central College Foundation of CAUC under Grant no. 3122014D027, the Experiment Technology Innovation Foundation of CAUC under Grant no. 01-14-01, and the College Students' Innovative Entrepreneurial Training Program (201510059069).

\section{References}

[1] S. Nikolakakos, "Stray currents-generation, interference effects and control," in Proceedings of the CORROSION, NACE International, San Diego, Calif, USA, March 1998.

[2] K. Zakowski and K. Darowicki, "Stray currents and pollution of the environment," Polish Journal of Environmental Studies, vol. 8, no. 4, pp. 209-212, 1999.

[3] K. J. Moody, "Stray current characteristics of DC transit systems," Materials Performance, vol. 33, no. 6, pp. 15-19, 1994.

[4] H. Hongna, L. Zili, Y. Hualei et al., "Criterion for pipeline AC interference corrosion in the public energy corridor," Oil \& Gas Storage and Transportation, vol. 31, no. 4, pp. 283-288, 2012.

[5] J. Zhao, Y. Teng, L. Liu et al., "Analysis and mitigation of stray current interference on xinda oil pipeline," Pipeline Technique and Equipment, vol. 2, p. 16, 2007.

[6] T. Zhang, M. Gong, X.-Z. Lin, X.-W. Zheng, and J. Xiong, "Protective effect of 3PE anti-corrosion coating associated with cathodic protection on pipeline," Corrosion \& Protection, vol. 33, no. 9, pp. 765-768, 2012.

[7] Q. Ding, Z. Li, and H. Hao, "Effects of AC interference on the optimum cathodic protection potential of X70 steel in soil solution," Anti-Corrosion Methods and Materials, vol. 60, no. 6, pp. 283-287, 2013.

[8] L. V. Nielsen, B. Baumgarten, and P. Cohn, "Investigating AC and DC stray current corrosion," in Proceedings of the 5th International Congress (CEOCOR '05), CIBE, Brussels, Belgium, 2005.

[9] W. H. Bruckner and O. G. Jansson, "Cathodic protection of lead cable sheath," Corrosion, vol. 15, no. 7, pp. 67-72, 1959.

[10] A. H. Al-Badi, "Safe separation distance between $132 \mathrm{kV}$ power lines and nearby metallic conductors," in Proceedings of the International Conference on Communication, Computer \& Power (ICCCP '07), Muscat, Oman, February 2007.

[11] Y. Yang, Z. Li, and Q. Ding, "Effectiveness of cathodic protection under AC interference and determination of the optimum protection potential," in Proceedings of the International Conference on Pipelines and Trenchless Technology (ICPTT '11), American Society of Civil Engineers, Beijing,China, October 2011.

[12] M. Ormellese, L. Lazzari, A. Brenna et al., "Proposal of Cp criterion in the presence of Ac-interference," in Proceedings of the CORROSION 2010, NACE International, San Antonio, Tex, USA, March 2010. 

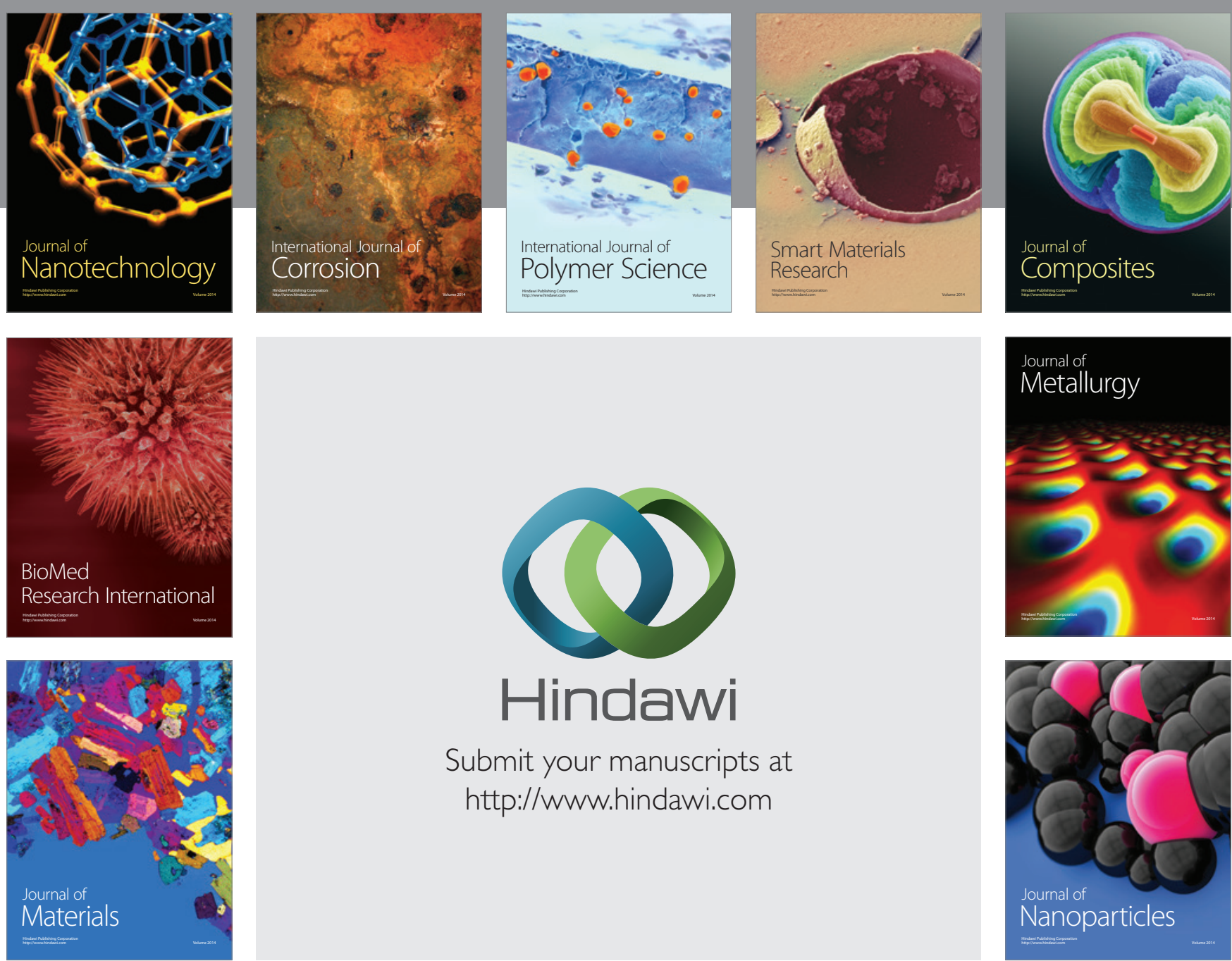

\section{Hindawi}

Submit your manuscripts at

http://www.hindawi.com

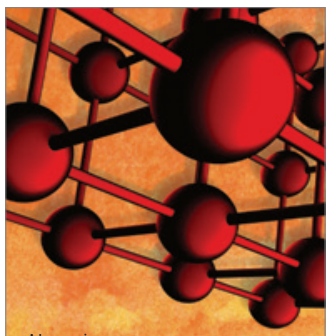

Materials Science and Engineering
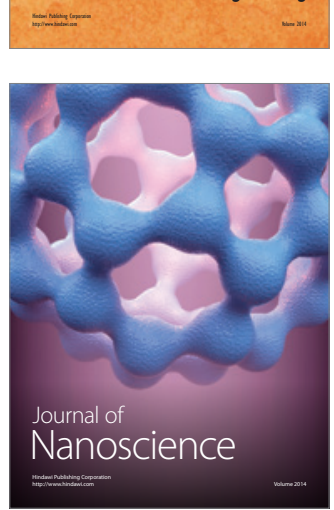
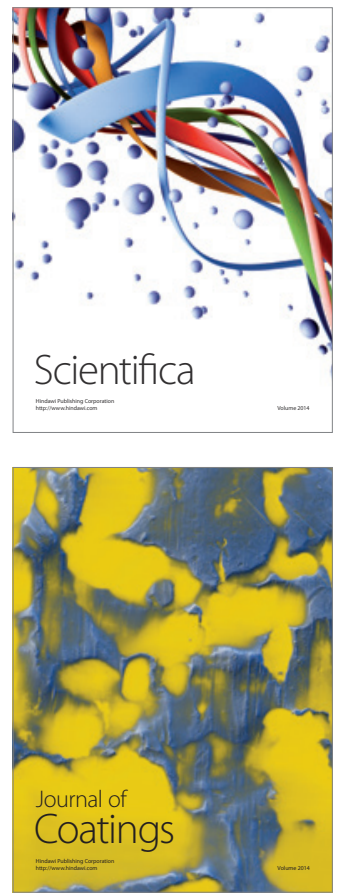
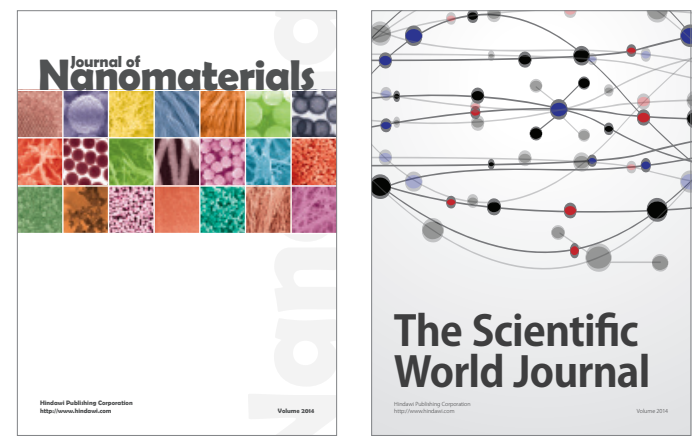

The Scientific World Journal
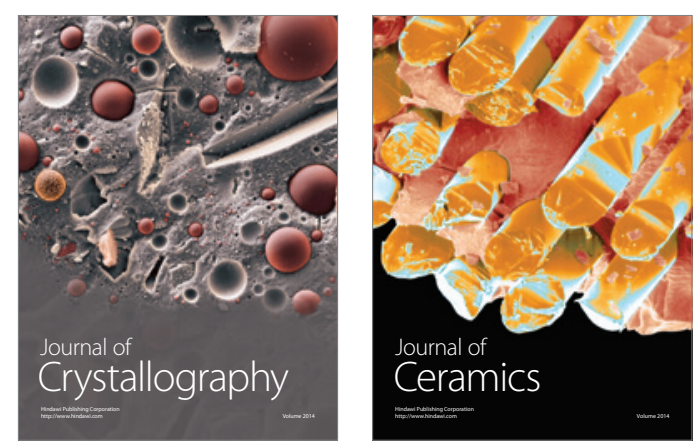
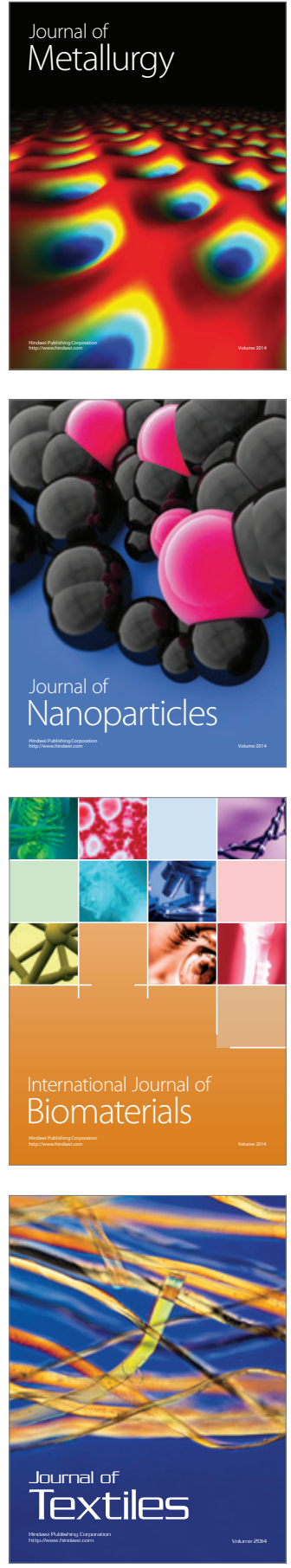